\title{
Conclusion
}

This book has argued that in order to fully understand the development of international principles and norms of human protection such as humanitarian intervention and R2P, we have to analyse France's conception of, and contribution to, human protection since the 1980s. To do so, the book has explained that we need to analyse a tale of two norms: France's domestic norm of human protection on the one hand, and the dominant international principle or norm of human protection at the time on the other. In order to fulfil this goal, it has developed a theoretical framework in which to analyse their historical interaction as the principles and norms evolved. By doing this, the book has brought together human protection, France's foreign policy and International Relations theory and has made key contributions to each field. This Conclusion provides an overview of these contributions while summarising the core findings of the book.

\section{Human protection}

As mentioned in the Introduction, France's role in human protection has been overlooked by the existing literature even though France is one of the five permanent members of the UN Security Council and a key European power, and has made important contributions to human protection since the 1980s. This shortfall has prevented us from fully understanding how key principles and norms of human protection have emerged and developed, and more specifically the impact - both positive and negative - that individual states like France can have - and have had - throughout their development. It has also stopped us from analysing the growing influence of these international principles and norms on states like France as they developed. By providing the first comprehensive account of France's relationship to human protection since the 1980s by investigating the impact that the interconnected yet distinct domestic and international norms of 
human protection have had on each other over time, the book has begun to correct this shortfall and suggests that we must expand the focus of the literature to other non-Anglo-Saxon states which are supportive of human protection if we are to ever gain a full understanding of human protection. ${ }^{1}$

Before discussing the growing influence of international norms such as R2P on France, it is important to reflect on what the book has taught us in terms of France's influence on human protection. It has argued that France has played a central role in human protection since the 1980s. France's role has at times been beneficial to the development of human protection principles and norms and the practice of human protection, but not always.

More specifically, the book has explained that during the late 1980s and early 1990s, France played a role as norm entrepreneur in the emergence of humanitarian intervention by promoting key resolutions to the UN General Assembly and Security Council and actively intervening worldwide for humanitarian purposes. As Gareth Evans argues, France's conception of human protection "had real resonance in the new circumstances of the post-cold war world" (2008a, 32). Additionally, throughout the 1990s France, under the leadership of François Mitterrand (1981-95) and then Jacques Chirac (1995-2007), helped shape the way the international community practised human protection through its military contribution to international interventions undertaken for humanitarian purposes.

However, during Chirac's presidency, even though France remained committed to intervening for humanitarian purposes, its normative contribution was more limited than in the late 1980s and early 1990s. During the second half of the 1990s, while assuming that the right to intervene already existed and was here to stay, France did not stop the norm contestation faced by humanitarian intervention and indeed even contributed to it, for instance by undertaking the controversial Opération Turquoise in Rwanda, and supporting coercive interventions in former Yugoslavia. Similarly, because, as Evans argues in clear and unambiguous terms, "the French were part of the problem" (2013b) by the end of the 1990s, France was excluded from the ICISS and therefore played no role in the emergence of R2P. In the early 2000s, however, France demonstrated that its voice still mattered despite its lack of norm entrepreneurship of R2P, in particular by making sure that the Iraq War did not receive the authorisation of the Security Council. It also intervened heavily for humanitarian purposes.

From 2006, Nicolas Sarkozy's various executives (2007-12), began to actively support R2P both diplomatically and militarily. This active support was not always beneficial to the development of the international norm. As the cases of Myanmar/Burma and Libya showed, France indeed ended 
up endangering its development - at times - by promoting a broad understanding of R2P. In view of the influence of France's domestic norm of human protection since the 1980s and its will to promote its status, and in light of the broad definition of R2P in 2005, the promotion by France of a broad understanding of R2P was not surprising. It demonstrated, however, the impact a state like France could have during the development of the international norm, even if it was not involved in its emergence.

After Libya, François Hollande (2012-17) and his executives became - to a certain extent - a more traditional promoter of the international norm since they no longer argued that R2P had French roots. France's support of R2P during that period was diplomatic and military, but also normative thanks to its key proposals such as the restraint of the veto power. Hollande's various executives, however, also continued to promote a wide understanding of the scope of the norm in order to ensure that it was implemented comprehensively and robustly.

\section{France's foreign policy}

The next key contribution of this book lies in the fact that it reshapes our understanding of France's foreign policy and allows us not only to better comprehend its past and contemporary foreign policy, but also to anticipate its future one. By shedding light on the importance of France's domestic norm of human protection over the years on the one hand and investigating the growing impact of international norms such as R2P on France's conception and practice of human protection on the other, it provides a new lens through which to understand and analyse France's foreign policy. As explained in more depth in the next section, "International Relations theory," R2P began to restrict where and how France could respond to mass atrocities during Sarkozy's presidency, and its influence progressively strengthened throughout Hollande's mandate.

Additionally, analysing the influence of France's domestic norm, which emerged in the 1980s, helps us to better understand France's commitment to protect, the various executives' broad understanding of human protection, and the fact that France only promoted the creation of a right to intervene in the domestic affairs of a state in order to fulfil its perceived duty to protect.

The book has also provided a better understanding of the relationship between various aspects of France's identity and its foreign policy. The various executives' obsession with being seen as 'the homeland of human rights', as well as with France's rank, has indeed contributed to France being actively involved in human protection. But as illustrated throughout the book, the executives' obsession with France's rank also influenced how 
they intervened for humanitarian purposes. One could argue that states will always endeavour to design their foreign policy in a way that promotes their image and status internationally, but as Grosser argues, "for [France], prestige constitutes an end in itself" $(1995,64)$. As a consequence, France's practice of human protection evolved over time in terms of the breadth of its interventions, the institutional framework chosen to intervene and the strategy used in the field in order to prevent situations where promoting human protection and promoting France's rank constituted conflicting goals. In other words, while its commitment to human rights has partly explained why France wanted to play a central role in human protection, the obsession with its status has explicated not only its active role, but also how it has implemented human protection.

This leads us to another contribution when it comes to France's foreign policy. By analysing France's military interventions for humanitarian purposes - which represent the majority of the interventions it has undertaken abroad - the book has revealed broader lessons in terms of France's priorities and its relations with global institutions, particularly the $\mathrm{UN}$, the European Union and NATO. It has shown France's military commitment to NATO in light of the means available to the organisation and the strong mandate of the operations it undertakes for humanitarian purposes. Similarly, it has demonstrated France's will to promote the European Union's foreign policy and its capacity to intervene for humanitarian purposes over time. Furthermore, it has showed that even though France avoided intervening through the UN for humanitarian purposes from the mid-1990s onwards because of the lack of means and the weaker mandates its interventions faced, it has considered it to be the central platform for discussing international issues. It has also been willing to support its interventions, either by providing limited troop contributions or via more substantial unilateral operations which support UN missions without being restrained by their narrow mandates.

The book has also demonstrated both variation and continuity in terms of where France has intervened for humanitarian purposes over the years. At the beginning of the 1990s, Mitterrand and his various executives favoured intervening worldwide. In the second half of the 1990s, in light of the change of domestic and international contexts and in order to fulfil France's perceived duty to intervene to protect without endangering its rank, Chirac's executives focused on Europe. The 2000s witnessed some continuity with the second half of the 1990s, with a strong focus on Europe, but the executives also began renewing their interventions in the Middle East and Africa. Hollande's presidency was more unusual since France mainly intervened militarily for humanitarian purposes in Africa, mainly 
because of domestic and international constraints, rather than because of a will to resume Françafrique practices.

\section{International Relations theory}

The book also makes a contribution to the literature on norm diffusion. It has emphasised the importance of taking into account the interplay between related yet distinct domestic and international principles and norms and has shown how this can be achieved by putting forward an innovative theoretical framework which builds on, yet overcomes some of the weaknesses of, the norm life cycle and the norm circulation models respectively put forward by Finnemore and Sikkink (1998) and Acharya (2015). ${ }^{2}$ It has argued that four key phases can be identified in the relationship between two specific domestic and international norms: entrepreneurship, localisation, subsidiarity and internalisation. Because norms are not static but rather are in constant evolution, these stages should not be seen as a unidirectional representation of the development of norms; instead each stage should be seen as one segment of their development that will be repeated as the international context evolves and/or new forms of contestation emerge. Even though this framework was designed specifically to study France's relationship to human protection over time, it can be used to study the interplay of other domestic and international norms and therefore makes a broader contribution to the literature on norm diffusion and IR theory more generally.

With regard to the focus of this book, the framework allowed us to better understand the emergence and development of key international principles and norms such as humanitarian intervention and $\mathrm{R} 2 \mathrm{P}$, since it allowed us to take into account the role played by specific states like France. It also helped us understand the way France has been influenced by these international normative developments as they strengthen. Following the discussion of the influence of France on humanitarian intervention and R2P in the section "Human protection", this section discusses the impact that these international principles and norms have had on France's conception and practice of human protection.

During the 1990s and early 2000s, while France's domestic norm of human protection was very influential on the various executives, the same cannot be said about humanitarian intervention and R2P. This lack of influence on France is not surprising since the impact of an international principle or norm on a state like France is only expected to be proportional to its strength, especially when a related domestic norm exists and 
is influential. Yet, as explained in the book, humanitarian intervention was a relatively weak international principle in the 1990s and R2P was only a concept in the early 2000 s.

Things began to change, however, when R2P started gaining international traction during Sarkozy's presidency and was consolidated during Hollande's. During Sarkozy's presidency, R2P began to restrict where France could intervene, while during Hollande's, it began to be internalised to a certain extent and thus influenced not only where France was involved but also why it was involved. Once again, this was to be expected since, as explained in more depth in Chapter 1, while a state like France can play a strong role in the emergence and development of an international norm like R2P, its influence progressively reduces as the international norm becomes stronger. In contrast, while an international norm can have a limited impact on a state like France during the early stages of its development - especially if that state has a related domestic norm - its influence will strengthen as it develops.

The beginning of the internalisation of R2P, however, did not signal the death of the domestic norm. The norm remained influential during both Sarkozy's and Hollande's presidencies: it influenced why France promoted a broad understanding of the international norm's scope, and why it was involved in human protection - including why it wanted to play a central role in the development and evolution of R2P. The ongoing influence of the domestic norm was facilitated by its strength and also by the fact that while R2P gained traction during Hollande's mandate, it remained contested.

The extent of the book's theoretical contribution also lies in the fact that it has examined a case in which an international principle or norm (humanitarian intervention and R2P) interacts with a state (France) that is positively disposed to it, but still has its own interpretation of what it should entail and how it ought to be understood by the rest of the international community in light of the influence of its own related yet distinct domestic norm (France's domestic norm of human protection). In this respect, it contrasts with the contributions by Amitav Acharya and others, who have tended to focus on cases in which states are resistant to or wary of the international principle or norm, and has thus provided a different and valuable view of how norms develop and interact.

\section{The way forward}

These contributions can help us to better anticipate the future. Given the strong impact of France's domestic norm of human protection on the various executives over time and also the growing influence of R2P, it can be assumed that France will remain committed to human protection in the 
future. When it decides to intervene militarily, it is likely to do so in a way that will help promote - or at the very least, not endanger - its rank, for instance, by collaborating with organisations such as NATO or by intervening unilaterally in support of multilateral operations, and by relying on strong mandates. It will also probably continue to promote the European Union's capacity to respond to atrocity situations.

In terms of France's specific relationship with R2P, it is likely that France's domestic norm of human protection will continue to exist in parallel with the international norm and that the two norms will - at times, although less often - clash with one another. The internalisation of the international norm suggests that France will keep promoting the international norm and will increasingly be influenced in terms of when and where it can intervene to protect.

However, in view of the ongoing influence of the domestic norm and France's practice of human protection over the last few decades, France will probably always try to promote a robust understanding of R2P where the use of force under pillar three is still seen as a possible option that must be used if other measures fail and a positive outcome is likely to occur. Similarly, it will continue to promote a broad understanding of the scope of R2P in order to include situations such as the destruction of cultural heritage. In light of the status of the international norm, this process will require reliance on extensive collaborations with other members of the international community, but it will likely be perceived as necessary for the executive to promote France's conception of human protection, and to fulfil the role it has to play in human protection.

As in the past, it can be expected that France's efforts will sometimes lead to the strengthening of the international norm, but they may also endanger it at times, though, theoretically speaking, to a lesser extent than in the past. Therefore anyone interested in human protection, France's foreign policy or norm diffusion should monitor France's current and future commitment to human protection and, more specifically, its relationship to R2P.

\section{Notes}

1 As mentioned in the Introduction, the literature has investigated the role played by Anglo-Saxon states and states which are wary of the principles and norms, such as the BRICS.

2 These limitations were discussed in Chapter 1. 